\title{
Towards Using MP4 Players in Teaching English Language: An Empirical Study
}

\author{
${ }^{1}$ Khalid Thabit and ${ }^{2}$ Fouad Dehlawi \\ King Abdulaziz University, Jeddah, Saudi Arabia
}

\begin{abstract}
Portable MP3/MP4 players, e.g. iPod, are mostly used for entertainment purposes and they are very popular among the youth. In this paper, we explore the possibility of using such devices as an aiding tool in the educational environment, and hypothesise that these devices would help improve learning, e.g. fluency in English. We report on a number of preliminary studies which suggest that the use of such devices helped students in English learning.
\end{abstract}

Keywords: - English Language Proficiency, Teaching Aids, Preloaded Portable Devices

\section{Introduction}

English is the medium of instruction in most disciplines at King Abdulaziz University, Saudi Arabia. The English Language Centre at the University and the Faculty of Engineering are taking keen interest in providing students the facilities to improve their language skills. But despite the efforts made, the equipment available in the laboratories remains in the use of students for only few hours a week, making it unlikely to achieve the required goals.

In this research, we attempt to provide a 24-hours-a-day laboratory to students listening to English language and watching the realities of life in practice. The idea is that the students will be provided with MP4 players loaded with materials in English. The students will be expected to watch and listen to such materials at their free times, in a mobile fashion. We hope that such an approach will not only develop interests in students learning English as a foreign language, this will also help improve their English language skills, particularly fluency.

Mobile learning is an effective way of learning being outside the teaching campus [1,2]. Most of the universities world-wise have access to the online resources, which are accessible to the students within the campus, but off-campus such resources are often restricted because of various security reasons, for example. The lectures or materials can be downloaded within the campus on mobile devices and learned any where any time. Mobile devices may include PDAs, smart phones, cellular phone, MP3/ MP4 players, mini notebooks like i-PADs etc. Such devices are often used for entertainment purposes, but a few researchers have used them for educational purposes as well [3, 4].

We aim to use MP4 players as an aiding tool to help entry-level students improve their English language skills. We hypothesise that the proper utilization of these new devices (MP4 players) in education would improve the learning outcomes, especially in English as a foreign language. We report on a number of preliminary studies which suggest that the use of such devices have a positive impact on both levels: performance and attitudinal.

\section{Related Work}

The idea of using mobile phones for English language teaching for Japanese college students has been tested by Throton and Houser [14]. In their work they utilized SMS capabilities to provide vocabulary instructions and mini lessons three times a day. Students participating in this project received much better grades than those who received paper lessons. This was an effective text based method. Liu [15] used audio clips for English pronunciation lessons. Chartrand and Pellowe [16] offered downloadable audio Podcasts that could be transferred to media players. The study showed successful learning material for teaching English for Japanese students.

While there are many research works using SMS and Podcast, only little work has been reported on using video clips for language learning on cell phones or portable devices. This was due to the fact of the large file size of video files and the small size of common cell phone. Moreover, the small screen size of mobiles discouraged the use of video clips. Furthermore, transferring video clips as MMS have been costly and there is no standardization of MMS as compared to SMS.

In our own work, we use preloaded MP4 players that have large screens and huge memory.

\section{Our Approach}

We use MP4 players as an aiding tool to help entry-level students improve their English language 
skills, particularly fluency in English. We adapt the study support video material from Cambridge University Training Center, adding subtitles in Arabic and making some minor edits. The editing is made to meet the objectives of the course "English Proficiency and Interchange" at King Abdulaziz University. The study materials are then loaded on MP4 players and a sample of fifteen (15) students are provided with these devices. The students were advised to watch and listen to such materials at their free times for a period of one month. The abilities of these students are then compared with a control group - details follow - to see if the use of MP4 players achieved the expected goals.

Both the control group and the experimental group were assessed at three stages: (1) before handing MP4 players to the students (Pre-Test), (2) after two weeks usage of the MP4 players (Mid-Test), and (3) after one month usage of the MP4 players (Final-Test). Finally, a small self-opinion study was administered with the experimental group to seek their opinion about the whole exercise.

We hypothesise that the experimental group will perform better than the control group, in the assessments. A confirmation of this hypothesis would mean that the English language abilities of those students who used MP4 players as an aiding tool were greatly improved as compared to those students who did not use MP4 players for the same purpose.

\subsection{Empirical Evidence}

We conducted a series of studies to test the viability of using entertainment technology devices to improve education, especially in teaching English. These studies were conducted on a sample of sixty (60) students of the English Language course "English Proficiency and Interchange", taught by the same teacher. We selected those students who belonged to the section of the students with low English background. Fifteen (15) of these students were further selected voluntarily to use MP4 players as a teaching aid, the experimental group; the remaining students formed the control group.

\subsubsection{Pilot Study}

Before conducting the studies proper, the students were initially assessed through a routine test to measure their achievement level in the course, Pre-Test. The purpose of this study was to make sure that the students are distributed uniformly, according to their English-level skills, in both the experimental and the control groups. Here, we assumed the default null hypothesis that the experimental group and control group will perform the same in the test.

A sample of 10 questions was prepared, including readability, comprehension and speaking proficiency questions. Every participant was presented with all ten questions. We found that both control group and experimental group students performed the same [control: $\square=38.14, \square=14.34$; experimental: $\square=43.93$, $\square=12.00]$ (cf. Table 1). A ttest further revealed that these differences are not statistically significant $[p=.16]$, confirming that the two groups are of the same capabilities.

\subsubsection{Experiment 1: Direct assessment}

In this experiment we conducted two assessments, one after two weeks of MP4 usage and another one after one month of MP4 usage. The materials used and the procedure to conduct the experiment is presented below.

\section{Material}

The study support video material was purchased from Cambridge University Training Center. The materials were edited by the instructor of the course "English Proficiency and Interchange" to meet the specific objectives of the course, set by the Faculty of Engineering. Additionally, the videos were augmented with Arabic subtitles, making it possible that the participants understand the conversation in English. However, we expected that after listening/watching the clip for a few time, the students will no longer need to look at the subtitles. The edited video materials were then loaded on MP4 players, model SPMP 3050.

\section{Participants and Procedure}

Fifty nine (59) entry-level students of the "English Proficiency and Interchange" course participated in the experiment; all the participants were taught by the same teacher, thereby minimising the risk of any nonexperimental factors that might have influenced the students' abilities. Amongst these fifteen (15) students (experimental group) voluntarily used MP4 players, loaded with the video materials as a teaching aid, for a period of one month. It is important to mention here that the MP4 players were not used during the lecture/class times; the students were advised to use them during their study time or any free time.

The (experimental group) participants were instructed how to use the services of MP4 players in this experiment; they were encouraged to use the players only for study purposes and were warned about the consequences of any misuse. They were also briefed about the purpose of the study. 
The students used these players for a period of one month. During this period, the students (the whole section of 59 students) were assessed through a routine mid-term examination; their grades were recorded for analysis, Mid-Test. After a period of one month, the students again went through a routine final-term examination, Final-Test.

\section{Results and Discussion}

Students' grades/scores in Mid-Test and Final-Test were recorded for analysis. The mean scores for both the experimental and control groups in each test, and their average scores (averaged over two tests) along with the mean variance are shown in Table 1. Two-tailed t-tests were used to test the statistical significance of the results.

The data indicate that both groups performed the same in Mid-Test [control: $\square=38.02, \square=13.34$; experimental: $\square=41.77, \square=12.19$ ]. A ttest further revealed that these differences are not statistically significant $[p=0.34]$, indicating that a rather short period of MP4 players' usage did not help students improve their capabilities significantly. However, we found that when the students had more experience, using the device for the educational purposes, they performed reasonably better (Final-Test) as compared to those students who did not use such aiding tools [control: $\square=45.32, \square=9.43$; experimental: $\square=51.87, \square=10.01$ ] . A t-test further revealed that these differences are statistically significant (at significance level 0.05) $[p=$ .03], confirming that the use of MP4 players helped students improve their capabilities significantly.

Even though the average scores of the experimental group are not significantly better than the control group $[p=0.08]$, there is a positive tendency in favour of the use of MP4 players [control: $\square=41.67$; experimental: $\square=46.82]$. This tendency indicates that a careful usage of MP4 players can benefit students improving their English language proficiency.

Table 1: Students' scores in two tests

\begin{tabular}{|c|c|c|c|c|}
\hline & Group & Number & Mean Score & Std. Deviation \\
\hline & Control & 44 & 38.02 & 13.34 \\
\hline Mid-Test & Experimental & 15 & 41.77 & 12.19 \\
\hline \multirow{3}{*}{ Final-Test } & Control & 44 & 45.32 & 9.43 \\
\hline & & & & \\
\hline & Experimental & 15 & $\underline{51.87}$ & 10.01 \\
\hline \multirow{2}{*}{ Average } & Control & 44 & 41.67 & $\mathrm{n} / \mathrm{a}$ \\
\hline & Experimental & 15 & $\underline{46.82}$ & $\mathrm{n} / \mathrm{a}$ \\
\hline
\end{tabular}

Due to small number of participants and limited time the experiment was run, another method of evaluation seemed essential. Therefore we conducted a self-opinion study involving only those students who were exposed in the usage of the MP4 players. We report on this study in the following section.

\subsubsection{Experiment 2: Self-opinion study}

In this study, a questionnaire was distributed to participants to get a feel of their attitudes and opinions about the usage of MP4 players for educational purposes. The questionnaire addressed, amongst other questions, the following questions:

How frequently they used the MP4 players?

Was the duration of the usage sufficient?

Did they find this exercise helpful?

Would they like to use such technology for other courses? 
We hypothesised that the majority of the students would appreciate the use of MP4 players in learning English, and found that our hypothesis was on the right track. Almost $80 \%$ students indicated that they used the device 2-3 times every day, $15 \%$ reported that they used the device more than 10 times daily, whereas only $5 \%$ students reported that they seldom used the device.

Mostly, the students were of the opinion that, even though they spent most of the time using the device, one month was not sufficient for this exercise. Almost $75 \%$ students indicated that the duration was not sufficient, $17 \%$ reported that the duration was sufficient and only $8 \%$ indicated that the duration was too long.

The students also appreciate the usage of the device; $52 \%$ students indicated that the device helped them in improving their English skills, only 19\% reported that the device had the negative impact on them, the remaining $29 \%$ indicated that there were no effects of using the device.

Interestingly, reasonably good number of students liked to opt for the similar tools in other courses too. More than $80 \%$ students showed their interest to use such devices in other courses; only 6\% students disliked the usage in future.

Overall, these results are very promising and suggestive that the use of technology in education not only improves the quality of education, it also increases students' interest in learning.

\section{Conclusion and Future Work}

In this paper, we explored the possibility of using entertainment devices like MP4 players as an aiding tool in the educational environment. We conducted empirical studies with students who had a poor background in English, but after using preloaded English Proficiency Course materials their language skills were greatly improved.

In particular, this limited experiment showed promising effects of using MP4 players on both levels, in entry-level English learning students: performance and attitudinal. An improvement in performance was witnessed after a reasonable duration of using the MP4 players. Over-all, the students liked the device and desired its use in other courses as well.

It is highly recommended the experiment be repeated for a whole semester, on a larger pool of students and may be with different courses. More material should be loaded on the devices, and some incentive mechanism should be devised to encourage more frequent use. This larger scale experiment would provide more feedback and shed light on other aspects before going into a campus-wide implementation of this technology. A parallel experiment is worthwhile to try other subject matters and smart mobile phones instead of dedicated devices.

\section{Acknowledgement}

This project was funded by the Deanship of Scientific Research (DSR), King Abdulaziz Uni-versity, Jeddah, under grant no. 113/427. The authors, therefore, acknowledge with thanks DSR technical and financial support.

\section{References}

[1] Seibu Mary Jacob and biju Issac, "Mobile Learning Culture and Effects in Higher Education" IEEE Multidisciplinary Engineering Education Magazine, Vol2, No. 2, June 2007.

[2] Seppälä, P. \& Alamäki, H., "Mobile learning in teacher training. Journal of Computer Assisted Learning", 19, 330-335, 2003.

[3] Chris Houser, Patricia Thornton, Kinjo Gakuin University, Japan, "Mobile Learning: Cell Phones and PDAs for Education", Proceedings of the International Conference on Computers in Education (ICCE'02) 0-7695-1509-6/02, 2002 IEEE.

[4] Lorrie Jackson, Technology circles are buzzing about new ways to use the iPod-- beyond music, Education World 200, also available from: http://blendede-du.com/2004/10/ ipod-and-education.html

[5] iPod in Education: The Potential for Teaching and Learning.

[6] images.apple.com/education/ipodpaper/iPod_in_Education_whitepaper.pdf

[7] iPod in education: Getting Started, images.apple.com/education/products/ipod/iPod_Getting_ Started_Guide.pdf

[8] iPod in Education: We Didn't See it Coming.

[9] stream.buffalo.edu/shared/devo/Coursecasting/CoursecastingApple/f.htm

[10] Education Podcast Directory,www.podcastingnews.com/forum/link_6.htm

[11] The big directory, www.podcastdirectory.com

[12] English as a Second Language Podcast, www.eslpod.com

[13] English as a Second Language (ESL) Podcasts, a4esl.org/podcasts/

[14] Thornton, P., \& Houser, C., "Using mobile web and video phones in English language teaching:Projects with Japanese college students" In B.Morrison, C. Green, \& G. Motteram (Eds.),Directions in CALL: Experience, experiments \&evaluation Hong Kong: English LanguageCentre, Hong Kong Polytechnic University, pp 207-224, 2003.

[15] Man Lee Liu, "From M-Learning to Learning-M" (From Mobile Learning to Mobile Programming Training), Proc. 3d IADIS International Conference Mobile Learning, Lisbon, Portugal, pp.237-241,2007.

[16] Chartrand, R., Pellowe B., " ELTPodcast.com - a Podcast and Website for Students and Teachers of English", Proc. 2nd International Wireless Ready e-Proceedings -Podcasting.

[17] Education and Mobile Assisted Language. Learning, Nagoya, Japan, pp.66-72, 2007. 